\title{
UMA ABORDAGEM BASEADA EM SISTEMAS DE INFERÊNCIA FUZZY TAKAGI-SUGENO APLICADA AO PLANEJAMENTO DA OPERAÇÃO DE SISTEMAS HIDROTÉRMICOS DE GERAÇÃO
}

\author{
Ricardo de Andrade Lira Rabêlo* \\ ricardor_uspeyahoo.com.br \\ Adriano Alber de França Mendes Carneiro ${ }^{\dagger}$ \\ adriano@sel.eesc.usp.br
}

\author{
Ricardo Augusto Souza Fernandes ${ }^{\dagger}$ \\ ricardo.asf@gmail.com \\ Rosana Teresinha Vaccare Braga ${ }^{\ddagger}$ \\ rtvb@icmc.usp.br
}

*Secretaria da Fazenda do Estado do Piauí - Av. Pedro Freitas, s/n Bloco C - Bairro São Pedro - Centro Administrativo, Cep.: 64.018-200 - Teresina - PI

${ }^{\dagger}$ Departamento de Engenharia Elétrica - EESC - USP - Av. Trabalhador São-carlense, 400 - CEP 13566-590 - São Carlos-SP

${ }^{\ddagger}$ Dep. de Sistemas de Computação ICMC - USP - Av. Trabalhador São-Carlense, 400 - CEP: 13560-970 - São Carlos-SP

\section{ABSTRACT}

The operation planning of generation hydrothermal systems, in systems with wide hydraulic participation, such as the Brazilian system, aims to determine an energy operating policy that specifies how the hydroelectric power plants must be operated so that the hydroelectric resources available are used with economy and reliability. This paper presents an application of Takagi-Sugeno fuzzy inference systems to determine an energy operation policy (Fuzzy Inference SystemBased Policy - FISBP) that represents the optimal operation of reservoir for electric generation, and also an analysis of the policy obtained and its application at operational simulation of hydrolectric systems. The policy is obtained through the energy operation optimization of hydroelectric plants. From this optimization it extracts the relationships between the stored energy of the system and the reservoir volume of each plant. These relationships are represented in the parameters of the consequents of the fuzzy rules of the Takagi-Sugeno inference model in order to reflect the optimal operating be-

Artigo submetido em 25/03/2010 (Id.: 01121)

Revisado em 29/03/2010, 02/04/2010, 07/09/2010

Aceito sob recomendação do Editor Associado Prof. Julio Cesar Stacchini Souza havior of the hydroelectric power plants. To illustrate the effectiveness of FISBP, it was evaluated through comparations with papallel policy; with operation policy based at functional aproximations that uses polynomials and exponential functions; and with the result obtained using the optimal operation of individualistic hydro plants. Through methodology proposed, it is intended to demonstrate the viability of the obtainment and the application of FISBP, and with results obtained, it is also intended to show the effectiveness and energetic gains reached.

KEYWORDS: Fuzzy Inference System, Takagi-Sugeno, Operation Planning, Hydrothermal Systems, Operation Simulation, Operation Policy.

\section{RESUMO}

O planejamento da operação de sistemas hidrotérmicos de geração, em sistemas com grande participação hidráulica, como é o caso do sistema brasileiro, visa determinar uma política de operação que especifique como as usinas hidroelétricas devem ser operadas, de forma que os recursos hidroelétricos sejam utilizados com economia e confiabilidade. Este trabalho apresenta uma aplicação de sistemas de infe- 
rência fuzzy do tipo Takagi-Sugeno, responsável por obter uma política de operação (PBSIF - Política Baseada em Sistema de Inferência Fuzzy) que represente a operação otimizada de reservatórios para geração de energia elétrica, bem como da análise desta política e sua aplicação na simulação da operação de sistemas hidroelétricos. A política proposta é obtida pela otimização da operação energética das usinas hidroelétricas. Desta otimização extraem-se as relações entre a energia armazenada do sistema e o volume do reservatório de cada usina. Estas relações estão representadas nos parâmetros dos consequentes das regras linguísticas fuzzy do modelo de inferência de Takagi-Sugeno. De forma a ilustrar a eficácia da PBSIF, ela foi avaliada por meio da comparação do seu desempenho com a política de operação em paralelo; com a política de operação baseada em aproximações funcionais, que utiliza funções polinomiais e exponenciais, obtidas através do método dos mínimos quadrados; e também com o resultado obtido através da operação otimizada a usinas individualizadas. Com a metodologia proposta, procura-se demonstrar a viabilidade da obtenção e aplicação da PBSIF, e com os resultados obtidos, pretende-se ilustrar a eficácia e os ganhos energéticos advindos.

PALAVRAS-CHAVE: Sistema de Inferência Fuzzy, TakagiSugeno, Planejamento da Operação, Sistemas Hidrotérmicos, Simulação da Operação, Política de Operação.

\section{INTRODUÇÃO}

O planejamento da operação de sistemas hidrotérmicos de geração tem como objetivo determinar uma política de operação, que especifique como os subsistemas térmico e hidráulico devem ser operados para que os recursos disponíveis para geração de energia elétrica sejam utilizados de forma eficiente. O problema do planejamento é bastante complexo devido a vários aspectos, tais como: a estocasticidade das vazões afluentes e do mercado de energia elétrica; a interconexão das usinas hidroelétricas em uma cascata; as características operacionais não lineares das usinas hidroelétricas e termoelétricas; o acoplamento temporal entre as decisões operacionais durante o horizonte de planejamento; e as restrições de transmissão do sistema elétrico (Cruz Jr and Soares, 1996; Leite et al., 2002; Oliveira et al., 2009).

Em sistemas hidrotérmicos de geração com grande participação hidráulica, a política de operação visa substituir, na medida do possível, a geração de origem complementar (usinas termoelétricas, importação de energia de outros sistemas e o déficit) pela geração de origem hidroelétrica (Soares, 1987; Yu et al., 1998). Assim, nestes sistemas hidrotérmicos, o planejamento da operação tem como ponto fundamental a determinação de uma política de operação para os reservatórios do sistema hidroelétrico de geração. A política de operação adotada pelo setor elétrico brasileiro é a política paralela (Marques et al., 2005). Nesta política de operação, os reservatórios são operados em paralelo, isto é, eles devem manter o mesmo percentual de seus volumes úteis. Esta política de operação tem como maior atrativo sua simplicidade, entretanto, ela não obedece aos princípios da operação otimizada dos reservatórios para geração de energia elétrica (Carneiro et al., 1990; Sacchi, Nazareno, Castro, Silva Filho and Carneiro, 2004; Silva Filho et al., 2003; Soares and Carneiro, 1991).

Para obter uma política de operação que represente o comportamento otimizado dos reservatórios, inicialmente, a operação do sistema hidroelétrico é otimizada sob as mais diversas condições operativas, as quais representam as várias situações que podem ser encontradas na prática. Com a otimização, obtém-se um conjunto de pontos de operação, que relacionam a energia armazenada no sistema hidroelétrico (energia que o sistema pode gerar ao esvaziar o volume útil de água do conjunto de reservatórios) com o estado do reservatório de cada usina hidroelétrica. Para que o conjunto de pontos de operação possa ser utilizado como indicativo para uma política de operação, deverá ser necessário o ajuste de funções que descrevam, pelo menos em média, o comportamento da operação energética otimizada dos reservatórios. Com estes ajustes, determina-se para cada usina a reservatório uma função que inspira-se e busca seguir a tendência da operação otimizada da usina para o sistema hidroelétrico considerado.

Vários trabalhos relacionam-se com a obtenção de políticas de operação, diferenciando somente na técnica empregada para o ajuste dos pontos obtidos relativos à operação otimizada, bem como na aplicação da política de operação obtida. Em (Soares and Carneiro, 1993), os autores utilizam funções polinomiais de terceiro grau para ajustar os pontos obtidos com a otimização da operação energética de forma a obter a política de operação. A política de operação alcançada foi testada comparativamente com a política de operação em paralelo, por meio de modelos de simulação e do reservatório equivalente.

Em (Carneiro and Kadowaki, 1996; Kadowaki, 1995), os autores fazem o ajuste dos pontos por um algoritmo que usou o método dos mínimos quadrados, obtendo funções polinomiais e exponencias para representar a política operacional. As funções obtidas foram utilizadas em um modelo computacional de simulação de forma a serem avaliadas comparando-se seu desempenho com a política de operação em paralelo e com o resultado obtido pela operação otimizada a usinas individualizadas, com o conhecimento prévio das vazões afluentes.

Já em (Cruz Jr and Soares, 1995; Cruz Jr and Soares, 1996; Cruz Jr and Soares, 1999), os autores empregam o método 
dos mínimos quadrados no ajuste das funções polinomiais, exponenciais e lineares por partes. Entretanto, as funções obtidas foram aplicadas na construção do reservatório equivalente de energia, ao invés da simulação da operação do sistema hidroelétrico, comparando-as com a política de operação em paralelo.

Em (Sacchi, Carneiro and Araújo, 2004a; Sacchi, Carneiro and Araújo, 2004b), são utilizadas Redes Neurais Artificiais (RNAs), mais especificamente as redes SONARX, para a obtenção de uma política de operação que siga os princípios da operação otimizada. A rede SONARX foi integrada a um simulador da operação de sistemas hidroelétricos, em que a cada instante de tempo, o conjunto rede-simulador decide quanto cada usina deve gerar.

Em (Silva Filho et al., 1999), é proposta uma metodologia para simulação da operação de usinas hidroelétricas utilizando RNAs com arquitetura RBF Radial Basis Function. A política de operação obtida utilizando a rede RBF visou reproduzir as complexas relações existentes entre os reservatórios de um sistema hidroelétrico durante sua operação otimizada. A idéia de utilizar redes RBF na operação de usinas hidroelétricas é fazer com que os comportamentos diferenciados que os reservatórios possuem durante a operação otimizada com conhecimento prévio das afluências possam ser "aprendidos" pela rede e utilizados durante a operação normal do sistema. Entretanto, apesar das RNAs serem conhecidas pelo bom desempenho quando utilizadas como aproximadores funcionais, estas não permitem ao usuário uma compreensão facilitada de como suas decisões foram realizadas, ou seja, são designadas como caixas pretas, devido a sua incapacidade de explicar como e por que suas respostas foram geradas. Além disso, necessitam de um grande conjunto de treinamento para garantir que os pesos sinápticos sejam ajustados de forma a fornecer soluções que generalizem o problema.

Uma aplicação bastante comum dos sistemas de inferência fuzzy Takagi-Sugeno é sua utilização para aproximação de funções (Ross, 2004). As expressões analíticas destas funções podem ser de difícil cálculo ou mesmo não estarem disponíveis. Nestes casos, são necessários sistemas capazes de aproximar o comportamento de tais funções a partir de dados práticos existentes. A existência de funções paramétricas nos consequentes de suas regras e a facilidade de ajuste a partir de um conjunto de dados de entrada e saída faz com que os sistemas de inferência fuzzy Takagi-Sugeno sejam intrinsicamente relacionados com a tarefa de aproximação de funções (Rezende, 2003). Neste trabalho, empregou-se um sistema de inferência fuzzy, pois procurou-se modelar, por meio de regras linguísticas, o modo aproximado de raciocínio (Mamdani, 1977), de forma a imitar a habilidade humana de tomar decisões racionais em um ambiente de imprecisões e incertezas. Isto porque, sistemas fuzzy são potencialmente capazes de expressar e processar, de uma maneira sistemática, informações imprecisas, incertas, mal definidas e vagas. Outra vantagem na aplicação de sistemas fuzzy devese ao fato dos especialistas do domínio poderem mapear, de forma consistente, e em torno de regras linguísticas, o seu processo de tomada de decisões, fazendo com que a estratégia de ação/controle do sistema fuzzy seja tão fundamentada e consistente quanto a deles.

Desta forma, este trabalho apresenta uma aplicação de sistemas de inferência fuzzy do tipo Takagi-Sugeno (Takagi and Sugeno, 1985), responsável por obter uma política de operação (PBSIF - Política Baseada em Sistema de Inferência Fuzzy) que represente a operação otimizada de reservatórios para geração de energia elétrica, bem como da análise desta política e sua aplicação na simulação da operação de sistemas hidroelétricos. De forma a ilustrar a eficácia da PBSIF, esta foi avaliada por meio da comparação do seu desempenho com a política de operação em paralelo; com a política de operação baseada em aproximações funcionais, que utiliza funções polinomiais e exponenciais (política baseada em funções polinomiais e exponenciais - PBFPE), obtidas através do método dos mínimos quadrados; e também com o resultado obtido através da operação otimizada a usinas individualizadas. Com isto, procura-se demonstrar a viabilidade da obtenção e aplicação da PBSIF, bem como os ganhos energéticos advindos.

A Seção 2 apresenta o problema do planejamento da operação de sistemas hidrotérmicos de geração enfocando seus horizontes, sua formulação, e a política de operação para sistemas hidroelétricos, além de apresentar o sistema hidroelétrico utilizado nos estudos de caso deste trabalho. Na Seção 3 , alguns dos fundamentos dos sistemas de inferência fuzzy Takagi-Sugeno são apresentados, bem como o sistema fuzzy proposto. A Seção 3 fornece ainda alguns exemplos dos consequentes das regras linguísticas fuzzy de algumas usinas a reservatório do sistema hidroelétrico. Na Seção 4 é feita uma discussão sobre o algoritmo de simulação utilizado para comparação das políticas de operação implementadas. A Seção 5 traz a aplicação das políticas de operação para o sistema hidroelétrico escolhido, enfatizando os principais resultados dos estudos de caso. A Seção 6 apresenta as discussões do trabalho, seguida pela Seção 7, na qual são apresentadas as conclusões e observações finais do trabalho como um todo. 


\section{PLANEJAMENTO DA OPERAÇÃO DE SISTEMAS HIDROTÉRMICOS DE GE- RAÇÃO}

\subsection{Sistema Hidroelétrico Utilizado}

A Figura 1 ilustra o sistema hidroelétrico utilizado nos estudos de caso deste trabalho. Este sistema é composto pelas usinas hidroelétricas do sistema sudeste brasileiro, o qual pode ser caracterizado como um sistema complexo, pois contém usinas de grande porte, interligadas em paralelo e em cascata.

\subsection{Horizontes de Planejamento}

A complexidade do planejamento da operação não pode ser acomodada por um modelo matemático único, tornando-se necessária a utilização de cadeias de modelos com diferentes horizontes de planejamento e graus de detalhe na representação do sistema hidrotérmico de geração (Pereira, 1985). Dessa forma, o planejamento da operação é dividido em diferentes horizontes de tempo. No sistema brasileiro, ele é dividido em horizontes de médio, curto e curtíssimo prazo (ou programação diária) (Leite, 2003; Leite et al., 2006). Os horizontes de planejamento de médio e curto prazo são conhecidos pela designação de planejamento energético, já que tratam do aspecto energético da operação (planejamento da operação dos recursos energéticos). Esta etapa do planejamento visa a otimização da operação de sistemas compostos por várias usinas, considerando aspectos estocásticos e hidráulicos do problema com maior relevância (Martinez et al., 2002). A divisão do planejamento energético em médio e curto prazo deve-se a dificuldade do manuseio simultâneo da estocasticidade das vazões afluentes e da demanda de energia, com a representação individualizada de cada usina hidroelétrica. $\mathrm{O}$ planejamento elétrico da operação (horizonte de curtíssimo prazo) busca compatibilizar a operação elétrica com a operação energética, de forma a respeitar as restrições elétricas da rede como os limites de transmissão das linhas, assegurando uma operação confiável para o sistema elétrico de potência como um todo (Rodrigues et al., 2004).

Neste trabalho, adotou-se o planejamento energético com horizontes de cinco anos, discretizados mensalmente, mas considerando-se a representação individualizada das usinas hidroelétricas. Para aplicações em ambiente competitivo, com usinas pertencentes a diferentes empresas, a representação individualizada das usinas hidroelétricas, normalmente adotada no planejamento de curto prazo, é muito interessante, principalmente porque ela permite que as decisões sejam tomadas a partir de modelos de otimização/simulação que conseguem avaliar as condições individuais de operação de cada aproveitamento. A simplificação da represen- tação agregada do sistema, adotada no planejamento de médio prazo, faz com que o parque gerador não seja aproveitado da forma mais eficiente possível, uma vez que o reservatório equivalente de energia não consegue representar as características operativas individuais das usinas e, consequentemente, de seus respectivos acoplamentos hidráulicos (Oliveira et al., 2009; Silva and Finardi, 2001). Esses fatores, portanto, levam a uma utilização ineficiente por parte do parque gerador hidráulico (Finardi, 1999). Desta forma, a representação individualizada de cada usina hidroelétrica é importante, visto que o objetivo principal do planejamento da operação energética é determinar as metas de operação de cada usina, a cada intervalo, respeitando o acoplamento hidráulico das diversas cascatas existentes no sistema, e que aproveite as possíveis diversidades hidrológicas entre os vários rios.

\subsection{Formulação Matemática}

O planejamento da operação de sistemas hidrotérmicos de geração, com representação individualizada das usinas hidroelétricas e com vazões afluentes determinísticas pode ser formulado conforme o seguinte problema de otimização:

$$
\begin{gathered}
\min \begin{array}{c}
\sum_{t=1}^{T} C V P_{t} \cdot 0,5 \cdot \Phi\left(D_{t}-H_{t}\right)^{2}+V\left(x_{T}\right) \\
E_{t}=D_{t}-H_{t}
\end{array} \\
\quad H_{t}=\sum_{i=1}^{N} k_{i} \cdot h l\left(x_{i, t}^{\text {med }}, u_{i, t}\right) \cdot \min \left[u_{i, t}, q_{i, t}^{\max }\right] \\
x_{i, t+1}=x_{i, t}+\left(y_{i, t}^{i n c}+\sum_{k \in \Omega_{i}} u_{k, t}-u_{i, t}-x_{i, t}^{e v a p}\right) \cdot\left[\frac{\Delta t_{t}}{10^{6}}\right] \\
u_{i, t}=q_{i, t}+v_{i, t} \\
x_{i, t}^{\min } \leqslant x_{i, t} \leqslant x_{i, t}^{\max } \\
u_{i, t}^{\min } \leqslant u_{i, t} \leqslant u_{i, t}^{\max } \\
q_{i, t}^{\min } \leqslant q_{i, t} \leqslant q_{i, t}^{\max } \\
x_{i, 0} \text { dado }
\end{gathered}
$$

onde:

- $T$ : número de intervalos do horizonte de planejamento;

- $N$ : número de usinas hidroelétricas;

- $C V P$ : coeficiente de valor presente;

- $E_{t}$ : geração térmica total [MW];

- $H_{t}$ : geração hidroelétrica total [MW];

- $D_{t}$ : demanda (mercado de energia elétrica) [MW];

- $x_{i, t}$ : volume armazenado no reservatório $i$ no final do intervalo $t\left[\mathrm{hm}^{3}\right]$;

- $x_{i, t}^{\text {med }}$ : volume médio armazenado no reservatório $i$ no intervalo $t\left[\mathrm{hm}^{3}\right]$; 


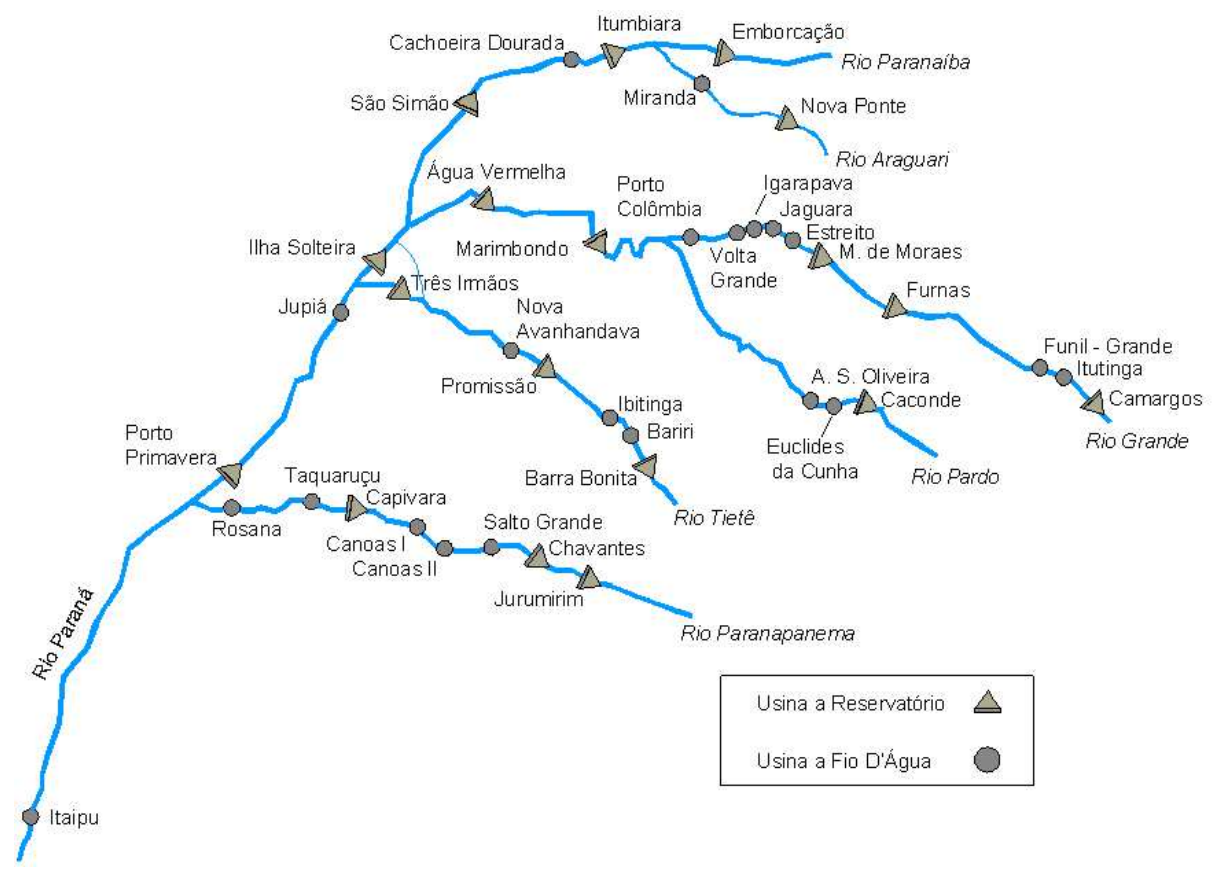

Figura 1: Sistema hidroelétrico utilizado.

- $x^{\text {evap }}$ : volume evaporado no reservatório $i$ no intervalo $t\left[\mathrm{hm}^{3}\right]$

- $h l_{i, t}$ : altura de queda líquida da usina $i$ no intervalo $t$ [m];

- $y^{i n c}$ : vazão afluente incremental (lateral) ao reservatório da usina $i$ no intervalo $t\left[\mathrm{~m}^{3} / \mathrm{s}\right]$;

- $q_{i, t}$ : vazão turbinada da usina $i$ no intervalo $t\left[\mathrm{~m}^{3} / \mathrm{s}\right]$;

- $u_{i, t}$ : vazão defluente da usina $i$ no intervalo $t\left[\mathrm{~m}^{3} / \mathrm{s}\right]$;

- $v_{i, t}$ : vazão vertida da usina $i$ durante o intervalo $t$ $\left[\mathrm{m}^{3} / \mathrm{s}\right]$;

- $x_{i, t}^{\max }, x_{i, t}^{\min }$ : limites máximo e mínimo de volume armazenado para o reservatório da usina $i$ no final do intervalo $t\left[\mathrm{hm}^{3}\right]$;

- $u_{i, t}^{\max }, u_{i, t}^{\min }$ : limites máximo e mínimo de vazão defluente para a usina $i$ on intervalo $t\left[\mathrm{hm}^{3}\right]$;

- $q_{i, t}^{\max }, q_{i, t}^{\min }$ : limites máximo e mínimo de vazão turbinada para a usina $i$ no intervalo $t\left[\mathrm{hm}^{3}\right]$;

- $\Delta t_{t}$ : número de segundos no $t[\mathrm{~s}]$;

- $\Omega_{i}$ : conjunto de índices das usinas imediatamente a montante da usina $i$.
A função objetivo é composta de dois termos, os quais representam o custo operacional durante o horizonte de planejamento $(\Phi)$ e os custos futuros associados com o estado de armazenamento final dos reservatórios das usinas hidroelétricas a reservatório $(V)$. Como o sistema brasileiro de produção de energia elétrica é um sistema hidrotérmico, com forte predominância da geração de origem hidráulica, para nossos propósitos, o sistema de geração complementar está sendo representado por uma usina termoelétrica equivalente que substitui todo o sistema não-hidráulico, inclusive o déficit de geração, visto como uma térmica fictícia. Assim, o custo operacional, o qual é dado pelo custo do combustível utilizado na operação das usinas termoelétricas, pelo custo de importação de energia de outros sistemas, e pelo custo da falta de suprimento de energia (penalidade devida ao não suprimento de carga), o chamado "custo de déficit", é representado por uma única função de custo das fontes nãohidráulicas. O custo futuro é uma condição terminal, utilizada nos modelos de otimização da operação energética, para equilibrar o uso da água durante o horizonte de planejamento e seu uso futuro (Martinez and Soares, 2002).

A igualdade (2) representa a restrição de atendimento à demanda de energia elétrica no intervalo $t$. A geração hidráulica total do sistema hidroelétrico é representada pela equação (3), dada pelo somatório das funções de produção hidráulica de cada usina hidroelétrica. A equação (4) representa a equação de balanço hídrico no reservatório. Essa restrição 
estipula que o volume armazenado final no estágio $t$ é igual ao volume inicial para esse estágio mais as vazões de entrada (vazões afluentes incrementais e vazões defluentes das usinas imediatamente a montante) menos as vazões de saída (turbinagem e vertimento) e o volume evaporado. A vazão de saída da usina corresponde a vazão defluente e equivale a soma da vazão turbinada com a vazão vertida, e está representada na equação (5). As restrições (6) e (7) representam os limites de armazenamento e de defluência das usinas hidroelétricas. Os limites apresentados nestas inequações variam no tempo, pois estes refletem as restrições operacionais das usinas e outras restrições associadas ao uso múltiplo da água, tais como: irrigação, controle de cheias, navegação, etc. A restrição (8) representa os limites mínimo e máximo de vazão turbinada, os quais podem estar associados a restrições físicas da própria usina ou a restrições elétricas. Os valores dos volumes iniciais dos reservatórios são dados (9).

\subsection{Política de Operação de Sistemas Hi- droelétricos}

As políticas de operação para sistemas hidroelétricos encontram-se presentes em várias etapas do planejamento da operação de sistemas hidrotérmicos de geração. Elas são necessárias no procedimento de agregação para obtenção do reservatório equivalente em energia (Arvanitidis and Rosing, 1970a; Arvanitidis and Rosing, 1970b), bem como para a simulação da operação visando a desagregacão das metas de geração hidráulica total entre as várias usinas (Soares and Carneiro, 1993). Elas também são importantes para uma avaliação energética de sistemas hidroelétricos de geração, por meio de simulações da operação. Adicionalmente, políticas de operação também são utilizadas no planejamento da expansão da geração do sistema hidrotérmico brasileiro (Carneiro and Kadowaki, 1996; Silva Filho and Carneiro, 2004).

A política de operação para sistemas hidroelétricos procura especificar o comportamento de cada usina a reservatório, a fim de estabelecer um comportamento relativo entre as mesmas. Ressalta-se que, a política de operação do sistema hidroelétrico é especificada para as usinas a reservatório, porque, exceto por pequenas variações de volume, praticamente não há controle direto sobre a operação das usinas a fio d'água. Somente as usinas com reservatórios de acumulação podem variar a quantidade de água armazenada e regularizar as vazões afluentes naturais ao sistema de forma significativa. Isto confere às usinas a reservatório a característica de pontos de controle da operação de um sistema hidroelétrico (Cicogna, 1999).

A política de operação para sistemas hidroelétricos leva à determinação da quantidade de energia elétrica produzida por cada uma das usinas, pela definição do estado de armazena- mento de cada reservatório. Tal política pode ser compreendida como um conjunto de regras de operação, uma para cada usina a reservatório do sistema, a qual define como estas usinas serão operadas de forma acoplada. Para implementar o acoplamento na operação do sistema hidroelétrico, deve-se especificar um parâmetro global, denominado fator de acoplamento da operação entre as usinas, denotado por $\lambda_{t}$, definido no intervalo $0 \leq \lambda_{t} \leq 1$. O fator de acoplamento da operação representa o valor normalizado do armazenamento do sistema de reservatórios em um determinado intervalo $t$ do horizonte de planejamento, e é calculado como a proporção entre a energia armazenada no sistema (o estado global de armazenamento dos reservatórios das usinas do sistema hidroelétrico) no intervalo $t$ e a máxima energia que pode ser armazenada no sistema. Com o fator de acoplamento, o volume de cada usina a reservatório é determinado pela seguinte equação:

$$
x_{i, t}\left(\lambda_{t}\right)=x_{i, t}^{\min }+f_{i}\left(\lambda_{t}\right) \cdot\left(x_{i, t}^{\max }-x_{i, t}^{\min }\right)
$$

onde:

- $x_{i, t}\left(\lambda_{t}\right)$ : volume operativo da usina $i$ em função do fator de acoplamento da operação para o intervalo $t$;

- $f_{i, t}\left(\lambda_{t}\right)$ : regra de operação, a qual expressa as regras de enchimento/esvaziamento do reservatório da usina $i$ em função do parâmetro $\lambda$ no intervalo $t$.

\section{SISTEMAS DE INFERÊNCIA FUZZY TAKAGI-SUGENO}

Os sistemas de inferência fuzzy são baseados em regras de produção que fazem uso das variáveis linguísticas para executar um processo de tomada de decisão. A base de conhecimento destes sistemas consiste em um conjunto de regras de produção fuzzy do tipo "se...então", e têm seu funcionamento baseado em três etapas: fuzzificação, procedimentos de inferência e defuzzificação.

Nos sistemas de inferência fuzzy, geralmente, consideram-se entradas não-fuzzy (precisas ou crisps); resultantes de observações ou medições (conjunto de dados, por exemplo), que é o caso da grande maioria das aplicações práticas. Em virtude disso, faz-se necessário efetuar uma conversão (fuzzificação) desses dados precisos para os conjuntos fuzzy de entrada. Desta forma, a fuzzificação é um mapeamento do domínio da variável crisp de entrada para o domínio fuzzy, representando a atribuição de valores linguísticos, descrições vagas ou qualitativas, definidas por funções de pertinência às variáveis de entrada. A fuzzificação é uma espécie de préprocessamento de categorias ou classes de sinais de entrada, a qual reduz o número de valores a serem processados. Uma 
menor quantidade de valores processados significa que há um menor esforço computacional (Simões and Shaw, 1999).

O modelo a ser implementado tem uma variável fuzzy de entrada (EAS), definida respectivamente no conjunto de termos lingüísticos (Muito Baixa, Baixa, Média, Alta e Muito Alta) (Figura 2). Por exemplo, no sistema de inferência fuzzy proposto, o qual tem por objetivo determinar a regra de operação das usinas do sistema hidroelétrico $\left(f_{i}\left(\lambda_{t}\right)\right)$, utilizando, como entrada, o fator de acoplamento da operação $\left(\lambda_{t}\right)$, há a necessidade de transformar esse dado de entrada em conjuntos fuzzy, porque sistemas fuzzy trabalham com termos primários (expressões linguísticas). Para que haja esta transformação, o valor $\lambda_{t}$ é avaliado mediante as funções de pertinência associadas à variável linguística correspondente (EAS), resultando o grau de pertinência de cada valor de entrada nos conjuntos fuzzy associados aos termos primários correspondentes.

A etapa da inferência fuzzy, também chamada lógica de tomada de decisão, é a responsável por avaliar os termos primários das variáveis de entrada aplicando as regras de produção e atribuindo respostas ao processamento. De forma resumida, o procedimento de inferência é responsável por processar os dados fuzzy de entrada juntamente com as regras, de modo a inferir as contribuições na saída fuzzy do sistema de inferência. Uma regra de produção típica do modelo de inferência fuzzy Takagi-Sugeno é: se $x$ é $F$ e $y$ é $G$, então, $z=f(x, y)$, onde F e G são conjuntos fuzzy e $f$ é uma função polinomial de $x$ e $y$. O procedimento de inferência no modelo Takagi-Sugeno, especificamente, consiste em obter todas as contribuições individuais $z_{i}$ advindas de cada uma das regras ativadas (disparadas). Após esta etapa, deve-se ponderar (combinar) todas as contribuições individuais para produzir a resposta final $z$. Desta forma, a saída numérica é calculada diretamente pela soma das saídas das regras, ponderada pelo grau de ativação (disparo) de cada uma delas $\left(\mu_{i}\right)$. Portanto, um processo de defuzzificação é desnecessário (Zimmermann, 2001). Este modelo foi proposto como um esforço para desenvolver uma abordagem sistemática de modo a gerar regras fuzzy a partir de um conjunto de dados de entrada e saída (Ross, 2004).

$\mathrm{Na}$ abordagem proposta nesta pesquisa, especializou-se um sistema fuzzy Takagi-Sugeno, composto por 5 regras de inferência, para cada usina a reservatório. A sintaxe da base de regras dos sistemas fuzzy implementados é apresentada a seguir:

- Regra 1: Se (EAS é Muito Baixa) Então $z_{1}=$ $f_{1}(E A S)=a_{1} \cdot E A S+b_{1}$

- Regra 2: Se (EAS é Baixa) Então $z_{2}=f_{2}(E A S)=$ $a_{2} \cdot E A S+b_{2}$
Tabela 1: Parâmetros dos consequentes das regras de inferência fuzzy para a usina de Emborcação.

\begin{tabular}{|l||l||l|}
\hline EAS & a & b \\
\hline Muito Baixa & 0,5272 & $-0,0188$ \\
\hline Baixa & 0,8928 & $-0,1013$ \\
\hline Média & 1,0796 & $-0,1776$ \\
\hline Alta & 1,2216 & $-0,2690$ \\
\hline Muito Alta & 1,4516 & $-0,4533$ \\
\hline
\end{tabular}

- Regra 3: Se (EAS é Média) Então $z_{3}=f_{3}(E A S)=$ $a_{3} \cdot E A S+b_{3}$

- Regra 4: Se (EAS é Alta) Então $z_{4}=f_{4}(E A S)=a_{4}$. $E A S+b_{4}$

- Regra 5: Se (EAS é Muito Alta) Então $z_{5}=$ $f_{5}(E A S)=a_{5} \cdot E A S+b_{5}$

Com a otimização da operação do sistema hidroelétrico, obtém-se um conjunto de pontos de operação, os quais relacionam a energia armazenada do sistema hidroelétrico com o volume operativo de cada usina a reservatório. Para cada uma das 5 regras que compõem cada sistema fuzzy, aplicase regressão linear (Bussab and Morettin, 2006) nos pontos pertencentes ao seu domínio de ativação, utilizando os pontos de entradas/saídas conhecidos, a fim de se determinar os parâmetros $\left(a_{i}, b_{i}\right)$ de cada uma das $(5 \cdot N)$ funções polinomiais relativas aos consequentes dos $N$ sistemas fuzzy. As Tabelas 1, 2, 3 e 4 apresentam os parâmetros dos consequentes das regras de produção fuzzy relativas à política proposta para algumas usinas a reservatório do sistema hidroelétrico modelado $^{1}$.

Com a determinação dos consequentes das regras linguísticas obtidos pela regressão linear, pode-se colocar o sistema fuzzy em operação. No caso particular, a operação de cada sistema de inferência fuzzy determina a regra de operação de cada uma das usinas do sistema hidroelétrico:

$$
f_{i}(\lambda)=\frac{\sum_{j=1}^{5}\left(z_{j} \cdot \mu_{j}\right)}{\sum_{j=1}^{5} \mu_{j}} ; i=1, \ldots, N
$$

\section{SIMULAÇÃO DA OPERAÇÃO DE SISTE- MAS HIDROELÉTRICOS}

Em várias etapas da abordagem ao problema do planejamento da operação, é necessário simular a operação do sis-

\footnotetext{
${ }^{1}$ A descrição dos parâmetros dos consequentes das regras de produção fuzzy destina-se aos leitores interessados, principalmente, em reproduzir estudos da simulação da operação energética, com a política baseada em sistemas de inferência fuzzy Takagi-Sugeno, para o sistema hidroelétrico sudeste brasileiro.
} 


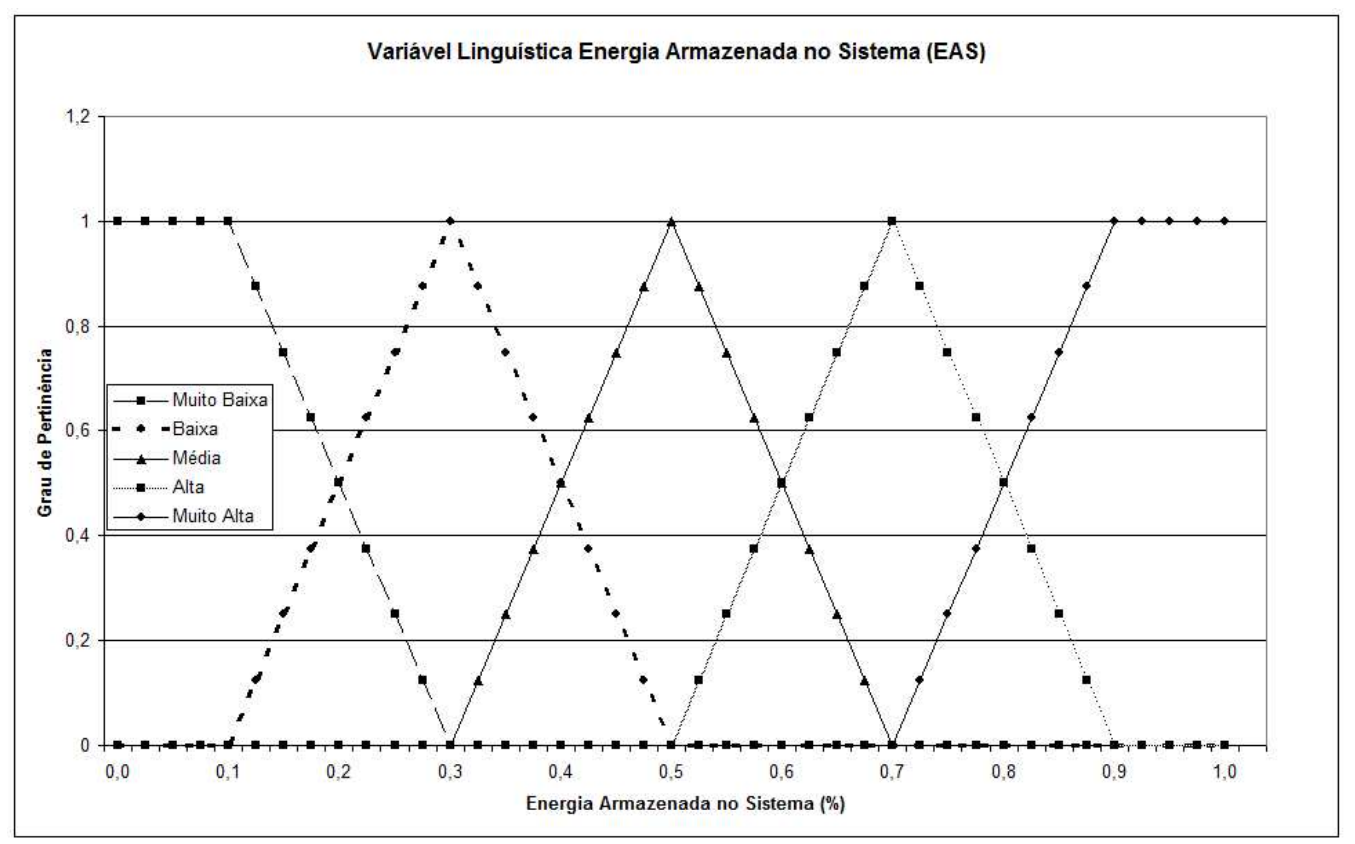

Figura 2: Variável linguística representando a energia armazenada no sistema.

Tabela 2: Parâmetros dos consequentes das regras de inferência fuzzy para a usina de Itumbiara.

\begin{tabular}{|l||l||l|}
\hline EAS & a & b \\
\hline Muito Baixa & 1,4329 & $-0,0757$ \\
\hline Baixa & 1,4357 & $-0,0744$ \\
\hline Média & 1,0728 & 0,0724 \\
\hline Alta & 0,9702 & 0,1341 \\
\hline Muito Alta & 0,4968 & 0,5114 \\
\hline
\end{tabular}

Tabela 3: Parâmetros dos consequentes das regras de inferência fuzzy para a usina de São Simão.

\begin{tabular}{|l||l||l|}
\hline EAS & a & b \\
\hline Muito Baixa & 2,5578 & 0,1792 \\
\hline Baixa & 0,7766 & 0,5879 \\
\hline Média & 0,1661 & 0,8414 \\
\hline Alta & 0,1414 & 0,8584 \\
\hline Muito Alta & 0,1008 & 0,8924 \\
\hline
\end{tabular}

Tabela 4: Parâmetros dos consequentes das regras de inferência fuzzy para a usina de llha Solteira.

\begin{tabular}{|l||l||l|}
\hline EAS & a & b \\
\hline Muito Baixa & 2,5544 & 0,3128 \\
\hline Baixa & 0,3530 & 0,8380 \\
\hline Média & 0,0505 & 0,9645 \\
\hline Alta & 0,0202 & 0,9823 \\
\hline Muito Alta & 0,0203 & 0,9809 \\
\hline
\end{tabular}

tema hidroelétrico, quer seja com o objetivo de estudar seu desempenho na construção do reservatório equivalente de energia, ou ainda nos procedimentos de desagregação destes sistemas. Deve-se citar ainda que a simulação também é utilizada no planejamento da expansão da geração. Neste trabalho, empregou-se um modelo computacional de simulação da operação de sistemas hidroelétricos, de modo a permitir a avaliação do desempenho da política de operação proposta (PBSIF). O modelo de simulação utilizado é parte de uma ferramenta computacional (Rabelo et al., 2008) que vem sendo desenvolvida pelos autores para a realização de estudos relacionados ao planejamento da operação de sistemas hidrotérmicos de geração. A ferramenta compreende, além do modelo de simulação, um modelo de otimização da operação energética de sistemas hidrotérmicos. Deve ser frisado que os autores aplicaram um processo de desenvolvimento (UML Components) (Cheesman and Daniels, 2001) baseado em componentes de software (Szyperski, 2002) para a cons- 
trução dos modelos computacionais supracitados, de forma a nortear o desenvolvimento da ferramenta, com a possibilidade de incluir ou modificar requisitos de uma maneira ordenada, mesmo quando a aplicação já se encontra em operação, como foi o caso da implementação da PBFPE no modelo de simulação (Rabelo et al., 2009).

\subsection{Algoritmo de Simulação da Operação}

Os algoritmos de simulação buscam reproduzir o comportamento operativo das usinas do sistema hidroelétrico sob condições operativas preestabelecidas. A Figura 3 resume os passos do algoritmo para simulação da operação energética de sistemas hidroelétricos. A seguir, cada passo apresentado na figura é explicado.

1. Carrega-se o valor dos volumes (armazenamento) iniciais do planejamento da operação energética;

2. Calculam-se os valores das vazões afluentes incrementais, da energia armazenada no sistema e da energia máxima armazenada no sistema, bem como, carrega-se o volume inicial do intervalo atual (volume final do intervalo anterior);

3. O valor inicial de $\lambda$ (fator de acoplamento da operação) é feito igual ao valor normalizado da energia armazenada no sistema. Este valor é obtido dividindo-se a energia armazenada no sistema (no início do intervalo atual) pela energia máxima armazenada no sistema;

4. O valor de $\lambda$ é utilizado pela política de operação para determinar o valor do volume armazenado no reservatório de cada usina (volume final);

5. Calcula-se o volume médio para as usinas, utilizandose a média entre os volumes iniciais e finais do intervalo em questão. Este cálculo é necessário, pois, geralmente, os reservatórios de acumulação têm o estado de armazenamento alterados entre o início e o final do intervalo. Caso o valor de volume, inicial ou final, seja utilizado nos cálculos energéticos (nível de montante, engolimento máximo, potência gerada, geração hidráulica máxima contínua, etc.), os resultados seriam menos realísticos do que os resultados obtidos com o volume médio do intervalo;

6. Determina-se o volume evaporado de cada usina do sistema hidroelétrico, a fim de avaliar a perda energética que ocorre, já que a água evaporada não é utilizada na geração de energia elétrica;

7. Conhecendo-se os volumes evaporado, inicial e final do intervalo atual, e as vazões afluentes incrementais a cada reservatório, determinam-se os valores de vazão defluente de cada usina, por meio da equação de balanço hídrico. Concomitantemente, realiza-se a resolução de conflitos, a qual destina-se a ajustar a decisão da política de operação às restrições operativas do sistema hidroelétrico. A restrição de volume é garantida pela política de operação, entretanto, o algoritmo de simulação deve contemplar a implementação dos limites operativos das vazões defluentes. No caso da vazão defluente violar os seus limites operativos, a operação energética desta usina é desacoplada da operação do resto do sistema hidroelétrico, com a fixação de sua vazão defluente neste limite e o consequente ajuste do volume final e médio. Por exemplo, se uma determinada usina violar o seu limite inferior de vazão defluente, fixa-se sua vazão defluente no limite mínimo estipulado, e corrige-se seu volume, por meio da equação de balanço hídrico. Uma violação no limite superior da vazão defluente deve ser tratada da mesma forma;

8. Calculam-se os valores das vazões afluentes efetivamente ocorridas a cada reservatório, visto que a interconexão hidráulica entre as usinas pode resultar em vazões afluentes a um reservatório, distintas de suas vazões afluentes naturais, devido a operação dos reservatórios localizados a montante;

9. Calculam-se os valores da geração hidráulica máxima contínua de cada usina, a qual é definida como a máxima potência ativa que pode ser gerada continuamente pela usina, considerando a potência máxima relacionada ao estado do reservatório, o fator de capacidade de geração máxima contínua, a taxa de manutenção programada e a taxa de indisponibilidade forçada;

10. Os limites mínimo e máximo da geração hidráulica são transformados em limites de vazão turbinada para cada usina, utilizando-se uma estimativa da produtividade média da usina. Estes valores mínimo e máximo da geração de cada usina podem ser obtidos a partir das restrições físicas da própria usina, bem como das restrições elétricas;

11. Determina-se o valor da vazão turbinada de cada usina, ou seja, a vazão que efetivamente gera energia. Neste trabalho, emprega-se a hipótese operativa de eliminar vertimentos turbináveis, ou seja, uma usina só verte quando não pode mais turbinar;

12. Especifica-se a geração hidráulica de cada usina através de sua função de geração;

13. Calcula-se a geração total do sistema hidroelétrico, utilizando-se os valores da geração hidráulica de cada usina. No caso em que a meta de energia não puder ser 


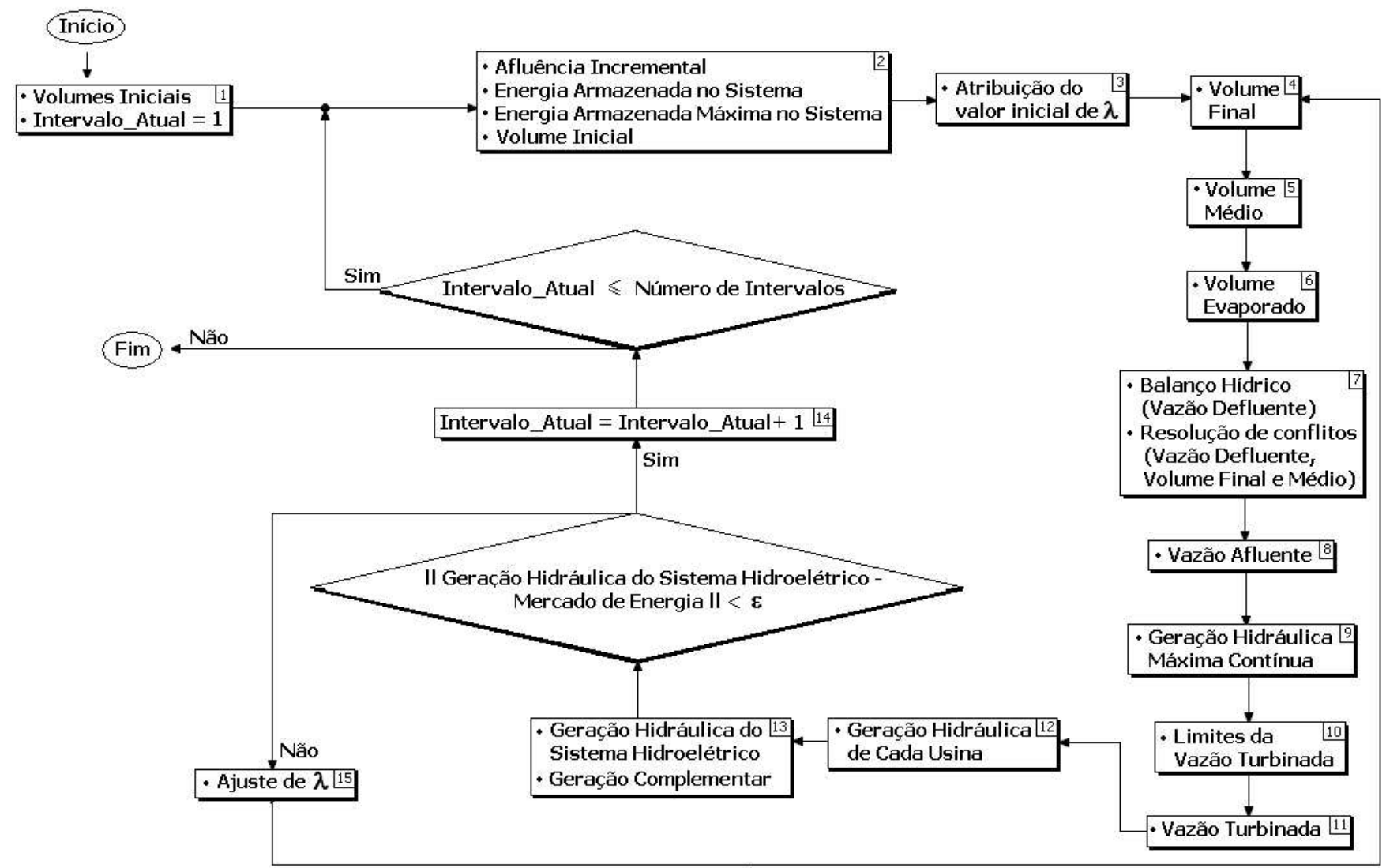

Figura 3: Algoritmo para simulação da operação energética.

atendida pelo parque hidroelétrico isoladamente, devese determinar a geração complementar para suprir o déficit de geração hidráulica;

14. Se a geração total for igual ao mercado de energia (sob uma determinada tolerância $\varepsilon$ ), incrementa-se o intervalo atual. Neste caso, deve-se testar se o intervalo atual ainda é menor que o número de intervalos do horizonte de planejamento. Caso esta condição seja satisfeita, retorna-se ao passo 2 e continua-se o processo de simulação. Caso contrário, finaliza-se a simulação da operação energética;

15. Se a geração total não for igual ao mercado de energia, ajusta-se o valor de $\lambda$. O ajuste de $\lambda$ é feito de forma a esvaziar (déficit de geração, no caso da geração hidroelétrica total ser menor que a meta de energia) ou encher (excesso de geração, no caso da geração hidroelétrica total ser maior que a meta de energia) cada reservatório.

\section{ESTUDOS DE CASO}

A simulação da operação propõe verificar como um sistema hidroelétrico de geração comportar-se-ia, caso fosse submetido a determinadas condições de operação (mercado de energia elétrica, política de operação, vazões afluentes, restrições operativas, volume inicial, etc.). Assim, para efetuar a comparação entre a política proposta (PBSIF), a política baseada em funções polinomiais e exponenciais (PBFPE), e a política paralela; as simulações da operação são realizadas sob as mesmas condições de operação. Portanto, as diferenças de comportamento na operação do sistema hidroelétrico resultarão unicamente das políticas operacionais utilizadas. Deve ser ressaltado que a comparação com a PBFPE só foi possível devido ao fornecimento dos parâmetros (coeficientes) pelos autores nos seus trabalhos. Desta forma, foi possível incorporar a PBFPE no modelo de simulação utilizado.

\subsection{Condições de Operação}

Foram realizados cinco estudos de caso, com o intuito de realizar uma comparação entre as três políticas de operação 
implementadas no modelo de simulação, sob diversas condições hidrológicas. A meta de geração hidráulica (ou mercado de energia elétrica) é considerada igual à geração hidráulica fornecida pelo modelo de otimização da operação energética, para os períodos de 1936 a 1941; 1951 a 1956; 1971 a 1976; 2000 a 2005 e com dados da MLT (Média de Longo Termo). As vazões afluentes naturais correspondem às vazões verificadas para os mesmos períodos do histórico. Desta forma, adotou-se o horizonte de planejamento de cinco anos, com discretização mensal de seus intervalos (60 meses). Adotouse o mês de Maio (início do período seco para a bacia hidrográfica do sistema sudeste) como o mês de início para todos os estudos de caso. Para efeito de comparações adicionais, foi realizada a otimização da operação energética do sistema hidroelétrico com as vazões afluentes realmente ocorridas nos períodos, de forma a obter-se a solução com o perfeito conhecimento das vazões afluentes para todo o horizonte de planejamento. Considerou-se, em todos os estudos de caso, o volume inicial armazenado nos reservatórios, como sendo igual ao volume máximo operativo.

\subsection{Resultados}

A Figura 4 ilustra a trajetória do déficit de energia armazenada (em \%) no sistema para as simulações da operação realizadas com as três políticas implementadas, utilizando as vazões afluentes da MLT. O déficit de energia armazenada no sistema é calculado como a subtração entre o valor da energia armazenada resultante através da solução otimizada ${ }^{2}$, e os valores da energia armazenada resultantes da aplicação das políticas de operação implementadas. Pode-se perceber um esvaziamento mais severo do conjunto dos reservatórios ao se utilizar a política de operação paralela, seguido por um esvaziamento menos rigoroso ao utilizar-se a PBFPE, e um esvaziamento ainda menos acentuado utilizando a PBSIF, o que implica uma maior eficiência na utilização dos recursos hidroelétricos de geração, através da política proposta (PBSIF).

Considerando-se o horizonte de planejamento envolvendo os anos 1936 - 1941, 1951 - 1956, 1971 - 1976 e 2000 2005, pode-se confirmar a maior eficiência fornecida pela política proposta quando comparada à política paralela, na utilização dos recursos hidroelétricos de geração. Ressaltase que quando comparada à PBFPE, a PBSIF só apresenta níveis mais reduzidos de energia armazenada (ou um déficit de energia armazenada mais elevado) no horizonte de 1971 a 1976. Pelas Figuras 5, 6, 7 e 8, pode-se perceber as trajetórias dos déficits de energia armazenada no sistema quando se aplica as políticas implementadas no modelo de simulação da operação.

\footnotetext{
${ }^{2}$ Limite superior de desempenho no uso dos recursos hidroelétricos de geração.
}

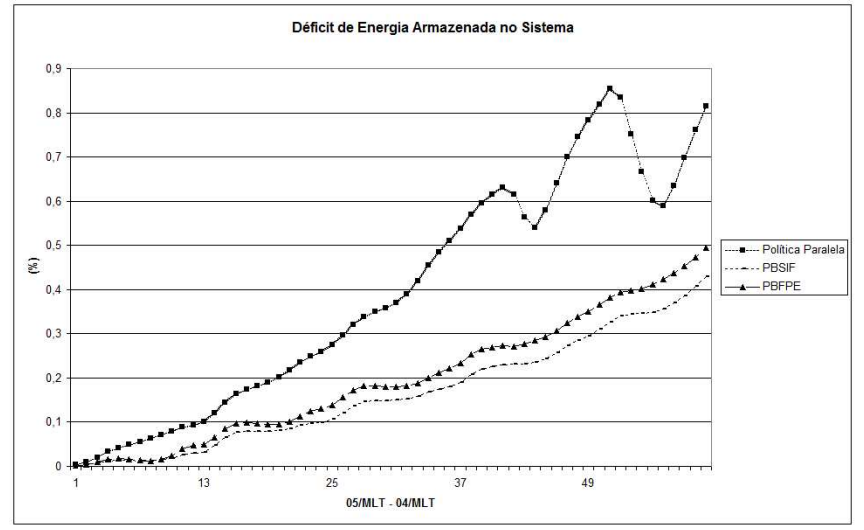

Figura 4: Trajetória do déficit de energia armazenada no sistema para a MLT.

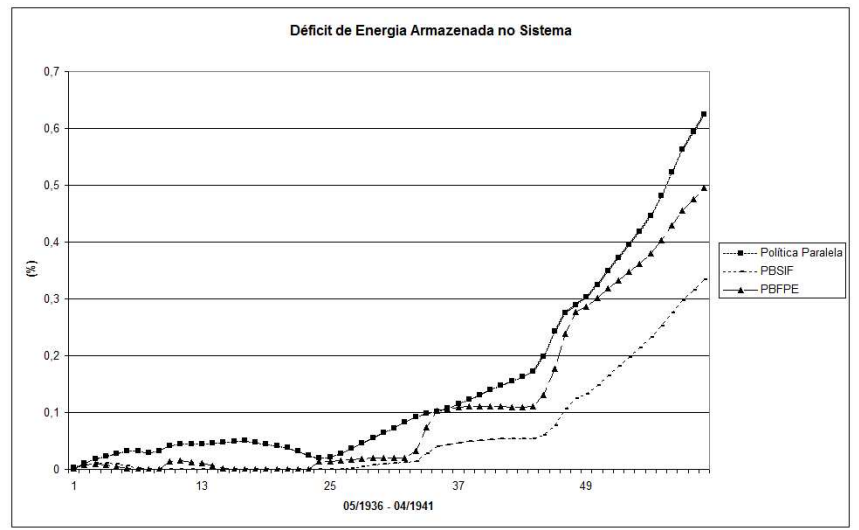

Figura 5: Trajetória do déficit de energia armazenada no sistema 1936 a 1941.

Na Figura 5, pode-se verificar a melhor utilização dos benefícios hidroelétricos de geração, pela política proposta, onde nota-se que o deplecionamento dos reservatórios é bem mais intenso quando se empregam a política paralela, e a PBFPE. Pode-se frisar ainda que, durante todo o horizonte de planejamento, a política proposta sempre apresentou valores mais baixos de déficit de energia armazenada no sistema, confirmando que esta política necessita utilizar menos água para atender ao mesmo mercado de energia elétrica. Adicionalmente, ao final do horizonte de planejamento, pode-se visualizar que a política paralela e a PBFPE não conseguem alcançar os níveis de armazenamento obtidos pela política proposta.

Baseado nas trajetórias de déficit da energia armazenada no sistema, pode-se afirmar que, na maioria dos estudos de caso realizados, a simulação da operação utilizando a política proposta maximiza os benefícios hidroelétricos do sistema hi- 


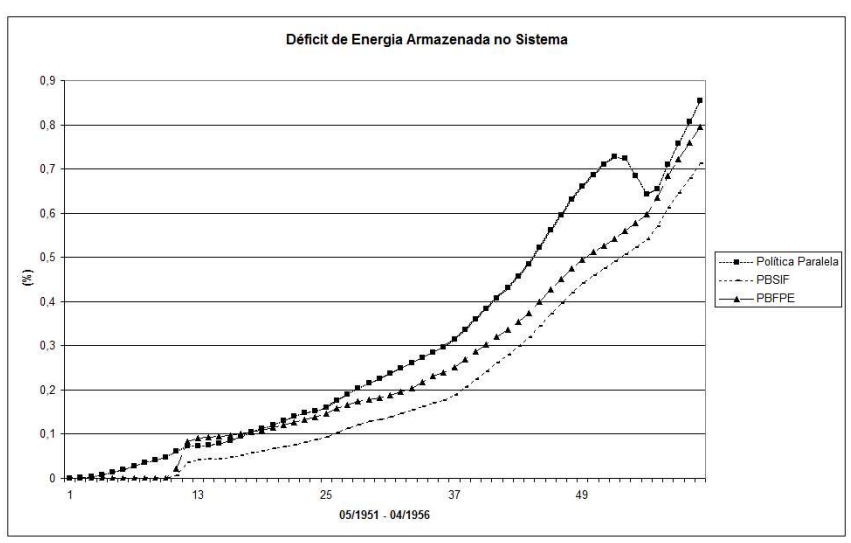

Figura 6: Trajetória do déficit de energia armazenada no sistema 1951 a 1956.

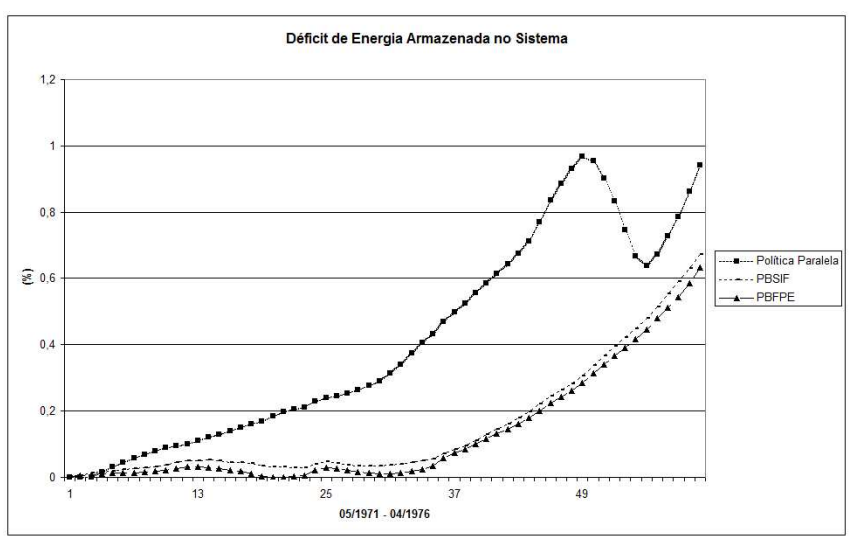

Figura 7: Trajetória do déficit de energia armazenada no sistema 1971 a 1976.

drotérmico de geração, pois atende ao mesmo mercado de energia elétrica, utilizando menos água armazenada nos reservatórios das usinas. Novamente, ao final do horizonte de planejamento, observa-se que a política de operação paralela não consegue manter os níveis de armazenamento próximos dos níveis de armazenamento estabelecidos pelas PBSIF e PBFPE. Pelo contrário, a política paralela chega ao final da simulação com o conjunto dos reservatórios com níveis mais críticos de armazenamento nos reservatórios, fazendo com que a confiabilidade e o custo da operação estejam extremamente comprometidos na operação contínua do sistema. Portanto, a PBSIF e a PBFPE permitem que a simulação da operação do sistema hidroelétrico seja consistente com a operação contínua do sistema, já que o mesmo não deixa de operar com o final do horizonte de planejamento. A Tabela 5 permite ao leitor uma comparação adicional, de forma a verificar numericamente a eficiência de cada política de operação com a solução otimizada.

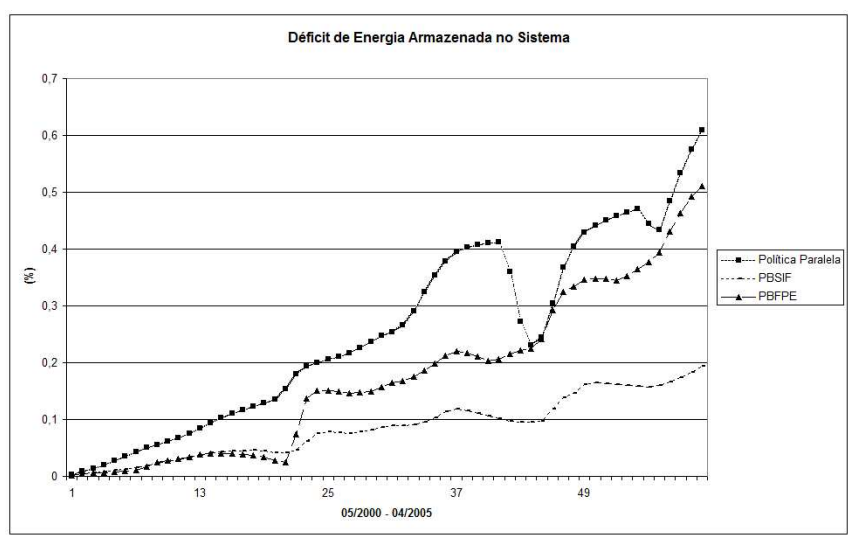

Figura 8: Trajetória do déficit de energia armazenada no sistema 2000 a 2005.

Tabela 5: Média da Energia Armazenada no Sistema Hidroelétrico [MW].

\begin{tabular}{|l||l||l||l||l|}
\hline $\begin{array}{l}\text { Hor. de } \\
\text { Planeja- } \\
\text { mento }\end{array}$ & $\begin{array}{l}\text { Pol. Pa- } \\
\text { ralela }\end{array}$ & PBFPE & PBSIF & $\begin{array}{l}\text { Sol. Oti- } \\
\text { mizada }\end{array}$ \\
\hline $1936-1941$ & 27865,83 & 29773,74 & 32299,55 & 34824,86 \\
\hline $1951-1956$ & 24232,82 & 26817,27 & 28851,86 & 38375,47 \\
\hline $1971-1976$ & 14329,13 & 27517,44 & 26544,69 & 33470,54 \\
\hline $2000-2005$ & 18151,44 & 21761,86 & 25847,11 & 29761,31 \\
\hline MLT & 17171,52 & 25950,09 & 27437,61 & 34991,9 \\
\hline
\end{tabular}

Ao utilizar os pontos de operação representativos da operação otimizada dos reservatórios para geração de energia elétrica, a política proposta (PBSIF) busca apresentar um comportamento diferenciado para cada reservatório das usinas do sistema hidroelétrico. Para isto, os parâmetros dos consequentes das regras de produção em cada sistema de inferência fuzzy Takagi-Sugeno foram calculados de forma a extrair o comportamento operativo específico para cada usina a reservatório, de acordo com sua posição na cascata e de acordo com o conhecimento dos especialistas (no caso, os autores) em relação ao estado dos reservatórios em função da energia armazenada no sistema (muito baixa, baixa, média, alta e muito alta).

O estado do reservatório afeta a produtividade da usina e, portanto, a trajetória de volume das usinas irá afetar significativamente a energia total gerada pelo sistema. Nos sistemas em cascata, este efeito torna-se mais acentuado nas usinas mais a jusante, por onde passa toda a água e, onde uma pequena perda de produtividade pode significar uma grande perda de energia, pois seriam aproveitadas as vazões defluentes das demais usinas a montante sem que seu volume útil esteja com uma condição favorável. Isto se deve, principal- 
mente, ao fato da água localizada no reservatório da usina a montante gerar energia elétrica, tanto quando passa pelas suas turbinas, como quando passa pelas turbinas da usina a jusante.

Com a política de operação proposta, as usinas de jusante, sempre que possível, permaneceram cheias, de forma a manter alta produtividade e, desta forma, valorizam os volumes de água que fluem por elas. Como a energia armazenada em uma usina é valorizada pela produtividade de todas as usinas a sua jusante, a altura de queda da usina mais a jusante, por exemplo, afeta a energia armazenada de todas as usinas da cascata (Carneiro et al., 1988). Desse modo, os parâmetros dos consequentes dos sistemas de inferência fuzzy priorizam níveis cada vez mais elevados de armazenamento nos reservatórios de montante para jusante na cascata de usinas. Com a especialização de um sistema de inferência fuzzy para cada usina a reservatório, a operação de cada usina reflete o papel que ela possui no sistema hidroelétrico, de acordo com sua localização na cascata.

A escassez de um produto, ou o seu elevado custo de produção, elevam seu preço de mercado. Com base nesse princípio econômico, o preço da energia elétrica no Brasil depende da energia armazenada nos reservatórios das usinas hidroelétricas, que por sua vez, em cada instante de tempo, depende das decisões operativas (política de operação) e das vazões afluentes aos reservatórios nos intervalos anteriores (Castro, 2004). Pelos resultados apresentados, pode-se verificar que com a política de operação proposta, o mercado de energia elétrica consegue ser atendido, com níveis mais elevados de energia armazenada no sistema hidroelétrico, o que favorece de forma potencial a um preço mais reduzido da energia elétrica além de uma maior confiabilidade na operação do sistema hidroelétrico.

Deve-se levar em conta que as comparações efetuadas com a solução otimizada tomaram como padrão a otimização com o conhecimento prévio das afluências (ótimo absoluto), caracterizando-a como um padrão extremamente rigoroso. Qualquer solução, por qualquer metodologia, deverá apresentar um grau maior ou menor de sub-otimalidade.

Uma observação obtida durante a análise dos resultados numéricos que merece destaque é que em alguns intervalos dos horizontes de planejamento, a simulação da operação, ao utilizar a política paralela, não conseguiu suprir completamente a meta de geração hidráulica (mercado de energia), devido ao severo esvaziamento dos reservatórios das usinas do sistema hidroelétrico. Neste caso, a decisão tomada pelo simulador consiste em fornecer a maior quantidade de energia hidráulica possível, e sinalizar um déficit de energia hidráulica para o intervalo simulado. Para suprir os déficits hidráulicos, emprega-se geração complementar. Ressalta-se que a con- vergência do algoritmo de simulação da operação já permite um déficit hidráulico de no máximo $0,5 \%$.

\section{DISCUSSÕES}

A política de operação proposta foi comparada, através de alguns estudos de caso, nas usinas hidroelétricas do sistema sudeste brasileiro, com a política de operação paralela e com a política baseada em aproximações funcionais utilizando funções polinomiais e exponenciais. A maioria dos resultados evidenciaram a eficiência da política proposta, tomando-se como parâmetros a média e as trajetórias de déficit da energia armazenada no sistema, obtidas pela simulação da operação do sistema hidroelétrico. Com relação à energia armazenada no sistema, os resultados ilustraram que a política proposta necessita de menos recursos hidráulicos sob as mesmas condições de operação que a política paralela e a PBFPE. Com relação à trajetória de armazenamento dos reservatórios da política de operação proposta, as usinas de jusante seguiram a tendência de permanecerem cheias, mantendo alta produtividade, e por consequência, os volumes de água que fluem pelas mesmas foram valorizados. Já as usinas de montante foram responsáveis pela regularização das vazões afluentes, amortecendo a disponibilidade irregular e aleatória das vazões afluentes naturais. No tocante à trajetória de geração complementar, em alguns horizontes de planejamento, a política paralela não foi capaz de suprir completamente a meta de geração hidráulica (mercado de energia elétrica), devido ao severo esvaziamento da energia armazenada no sistema hidroelétrico. Portanto, para suprir esta situação de déficit hidráulico, emprega-se a geração complementar do sistema hidrotérmico de geração.

Desta forma, verifica-se que a política proposta pode assegurar um fornecimento mais confiável e econômico da energia elétrica. Econômico porque a política proposta necessita de menos recursos hidráulicos de geração que a política paralela e a PBFPE. Confiável porque a política proposta permite a operação do sistema hidroelétrico com níveis superiores de armazenamento nos reservatórios, diminuindo a possibilidade de déficits hidráulicos do sistema hidrotérmico de geração. Portanto, pode-se evidenciar a potencialidade da política proposta na utilização dos recursos hidráulicos, voltados para a geração de energia elétrica.

Adicionalmente, ao final de todos os horizontes de planejamento, observou-se que a política de operação paralela não consegue igualar os níveis de energia armazenada do sistema hidroelétrico com os níveis estabelecidos pela PBSIF e pela PBFPE. Portanto, a política proposta, além de maximizar os benefícios dos recursos hidroelétricos de geração durante o horizonte de planejamento, ainda garante uma maior confiabilidade e um menor custo de operação do sistema hidrotérmico de geração na continuidade da operação do sistema, 
ao chegar ao final do horizonte de planejamento com níveis mais elevados de água armazenada nos reservatórios. Diferentemente, a política paralela chega ao final do horizonte de planejamento de algumas simulações da operação com todos os reservatórios quase vazios, fazendo com que a confiabilidade e o custo da operação estejam extremamente comprometidos na operação contínua do sistema.

\section{CONCLUSÕES}

Pelos resultados encontrados, a política de operação baseada no sistema de inferência fuzzy de Takagi-Sugeno procura estabelecer um comportamento distinto para o conjunto de reservatórios, de forma a maximizar a energia armazenada no sistema durante a simulação da operação do sistema hidroelétrico de geração. Este comportamento é obtido por meio da operação específica para cada reservatório, de acordo com sua posição na cascata. Com a influência predominante do efeito cota, as usinas cujo volume do reservatório não têm grande influência na energia armazenada no sistema hidroelétrico possuem prioridade de deplecionamento. Já as usinas cujo volume operativo do reservatório têm grande influência na energia armazenada do sistema apresentam prioridade de enchimento. Como a energia armazenada em um sistema hidroelétrico é valorizada pela produtividade das usinas mais a jusante, a operação realizada pelo sistema de inferência fuzzy enfatiza o enchimento de jusante para montante, e o deplecionamento de montante para jusante. Portanto, os reservatórios de montante, com a função adicional de amortecer a sazonalidade das vazões afluentes, são os que apresentam maiores oscilações no seu nível de armazenamento. Ressalta-se que o conhecimento das oscilações de volume, em função do posicionamento na cascata, encontra-se representado por meio das regras de produção fuzzy.

Ao optar-se por um sistema de inferência fuzzy para determinar o volume operativo de cada usina hidroelétrica, obtém-se uma estratégia de ação/controle que pode ser monitorada e interpretada, inclusive do ponto de vista linguístico. Outra vantagem encontrada, na aplicação dos sistemas de inferência fuzzy, refere-se à inclusão da experiência do grupo de pesquisa no estudo do comportamento otimizado dos reservatórios para geração de energia elétrica, na definição dos termos primários (conjuntos fuzzy) da variável linguística e na construção da base de regras de produção. Deve ser frisado que, como trabalhos futuros, algumas melhorias ainda podem ser investigadas em relação aos parâmetros do sistema de inferência fuzzy, principalmente no ajuste das funções de pertinência, do número de regras e dos consequentes das regras empregando-se técnicas como RNAs ou Algoritmos Genéti$\cos$ (AGs).

\section{AGRADECIMENTOS}

Os autores gostariam de agradecer ao Prof. Dr. Ivan Nunes da Silva da Universidade de São Paulo (Escola de Engenharia de São Carlos, Departamento de Engenharia Elétrica). Os autores também agradecem o suporte financeiro da SEFAZPI (Secretaria da Fazenda do Estado do Piauí) e da FAPESP (Fundação de Amparo à Pesquisa do Estado de São Paulo).

\section{REFERÊNCIAS}

Arvanitidis, N. V. and Rosing, J. (1970a). Composite Representation of a Multireservoir Hydroelectric Power System, IEEE Transactions on Power Apparatus and Systems PAS-89(2): 319-326.

Arvanitidis, N. V. and Rosing, J. (1970b). Optimal Operation of Multireservoir Systems Using a Composite Representation, IEEE Transactions on Power Apparatus and Systems PAS-89(2): 327-335.

Bussab, W. O. and Morettin, P. A. (2006). Estatística Básica, Editora Saraiva.

Carneiro, A. A. F. M. and Kadowaki, M. (1996). Regras de operação para grandes sistemas hidroelétricos em cascata, Anais do 11o Congresso Brasileiro de Automática.

Carneiro, A. A. F. M., Soares, S. and Bond, P. S. (1990). A Large Scale of an Optimal Deterministic Hydrothermal Scheduling Algorithm, IEEE Transactions on Power Systems 5(1): 204-211.

Carneiro, A. A. F. M., Soares, S. and Carvalho, M. F. H. (1988). Um modelo adaptativo para o planejamento da operação de sistemas hidrotérmicos de potência, Anais do 7 o Congresso Brasileiro de Automática, pp. 823829.

Castro, R. (2004). Análise de Decisões sob Incertezas para Investimentos e Comercialização de Energia Elétrica no Brasil, $\mathrm{PhD}$ thesis, Faculdade de Engenharia Elétrica da Universidade Estadual de Campinas.

Cheesman, J. and Daniels, J. (2001). UML components, Addison-Wesley Boston.

Cicogna, M. A. (1999). Modelo de Planejamento da Operação Energética de Sistemas Hidrotérmicos a Usinas Individualizadas Orientado por Objetos, Master's thesis, Faculdade de Engenharia e Computação, UNICAMP.

Cruz Jr, G. and Soares, S. (1995). Non-parallel composite representation of hydroelectric systems for long-term hydrothermal scheduling, IEEE Power Industry Computer Applications Conference, pp. 566-571. 
Cruz Jr, G. and Soares, S. (1996). Non-Uniform Composite Representation Hydroelectric Systems for LongTerm Hydrothermal Scheduling, IEEE Transactions on Power Systems 11(2): 702-707.

Cruz Jr, G. and Soares, S. (1999). General Composite Representation of Hydroelectric Systems, Power Industry Computer Applications, 1999. PICA'99. Proceedings of the 21 st 1999 IEEE International Conference, pp. 177182.

Finardi, E. C. (1999). Planejamento da operação de sistemas hidrotérmicos utilizando computação de alto desempenho, Master's thesis, Universidade Federal de Santa Catarina.

Kadowaki, M. (1995). Simulação da Operação de Sistemas Hidroelétricos de Potência a Usinas Individualizadas com Regras Otimizadas, Master's thesis, Dissertação de Mestrado, Escola de Engenharia de São Carlos, Universidade de São Paulo, São Carlos, Brasil.

Leite, P. T. (2003). Aplicação de Técnicas de Inteligência Artificial no Planejamento da Operação de Sistemas Hidrotérmicos de Potência, PhD thesis, Escola de Engenharia de São Carlos. Universidade de São Paulo.

Leite, P. T., Carneiro, A. A. F. M. and Carvalho, A. C. P. L. F. (2002). Energetic Operation Planning Using Genetic Algorithms, IEEE Transactions on Power Systems 17(1): 173-179.

Leite, P. T., Carneiro, A. A. F. M. and Carvalho, A. C. P. L. F. (2006). Aplicação de Algoritmos Genéticos na Determinação da Operação Ótima de Sistemas Hidrotérmicos de Potência, SBA: Controle \& Automação Sociedade Brasileira de Automática 17: 81-88.

Mamdani, E. H. (1977). Application of Fuzzy Logic to Approximate Reasoning Using Linguistic Synthesis, IEEE Transactions on Computers 26(12): 1182-1191.

Marques, T. C., Cicogna, M. A. and Soares, S. (2005). Assessment of energy availability of hydro system under different operation policies, Proceedings of IEEE Power Tech .

Martinez, L., Ballini, R. and Soares Filho, S. (2002). Influência da condição terminal no planejamento energético de sistemas hidrotérmicos, XIV Congresso Brasileiro de Automática pp. 1810-1815.

Martinez, L. and Soares, S. (2002). Comparison between closed-loop and partial open-loop feedbackcontrol policies in long term hydrothermal scheduling, IEEE Transactions on Power Systems 17(2): 330-336.
Oliveira, E. J., Marcato, A. L. M., Rocha, R. S., Oliveira, L. W., Silva Jr., I. C. S. and Pereira, J. L. R. (2009). Influência da variação da produtividade das usinas hidrelétricas no cálculo da energia firme, SBA: Controle \& Automação. 20(2): 247-255.

Pereira, M. V. F. (1985). Optimal scheduling of hydrothermal systems - an overview, IFAC Symposium on Planning and Operation of Electric Energy Systems.

Rabelo, R. A. L., Carneiro, A. A. F. M. and Braga, R. T. V. (2009). Component-based development applied to energetic operation planning of hydrothermal power systems, Proceedings of IEEE Bucharest PowerTech.

Rabelo, R. A. L., Lopes, W. N. M., Carneiro, A. A. F. M. and Braga, R. T. V. (2008). Análise, projeto e implementação orientado a objetos aplicados ao planejamento da operação energética de sistemas hidrotérmicos de potência, XVII Congresso Brasileiro de Automática.

Rezende, S. O. (2003). Sistemas Inteligentes: Fundamentos e Aplicações, Ed. Manole.

Rodrigues, L. G. L., Carneiro, A. A. F. M. and Costa, G. R. M. (2004). The study of electric-energetic interaction in the short-very-short-term operation planning using opfac, IEEE/PES T\&D 2004 Latin America Convention and Exhibition.

Ross, T. J. (2004). Fuzzy Logic with Engineering Applications, Wiley.

Sacchi, R., Carneiro, A. A. F. M. and Araújo, A. F. R. (2004a). Operation policies for hydropower systems: Using the unsupervised sonarx neural network, IEEE Power Systems Conference \& Exposition .

Sacchi, R., Carneiro, A. A. F. M. and Araújo, A. F. R. (2004b). A rbf network trained by the sonarx model and applied to obtain the operation policies of the hydropower systems, 8th Brazilian Symposium on Artificial Neural Networks.

Sacchi, R., Nazareno, J. S., Castro, M. A. A., Silva Filho, D. and Carneiro, A. A. F. M. (2004). Economics principles of the hidrothermal power systems operation, $I X$ Symposium of Specialists in Electric Operational and Expansion Planning.

Silva, E. L. and Finardi, E. C. (2001). Planning of Hydrothermal Systems Using a Power Plant Individualistic Representation, 2001 IEEE Porto Power Tech Proceedings, Vol. 3.

Silva Filho, D., Ballini, R. Soares Filho, S. and Carneiro, A. A. F. M. (2003). Interpretação linguística da operação Ótima de uma usina hidroelétrica através de redes 
neurais nebulosas adaptáveis, SBA: Controle \& Automação. 14(3): 330-337.

Silva Filho, D. and Carneiro, A. A. F. M. (2004). Dimensionamento Evolutivo de Usinas Hidroelétricas, Sba: Controle \& Automação Sociedade Brasileira de Automática 15: 437-448.

Silva Filho, D., Carneiro, A. A. F. M. and Araújo, A. F. R. (1999). Redes RBF Aplicadas à Simulação da Operação de Usinas Hidroelétricas, IV Congresso Brasileiro de Redes Neurais, pp. 275-280.

Simões, M. G. and Shaw, I. S. (1999). Controle e modelagem fuzzy, Edgard Blucher: FAPESP.

Soares, S. (1987). Planejamento da Operação de Sistemas Hidrotérmicos, Revista SBA: Controle e Automação 1(2): 122-131.

Soares, S. and Carneiro, A. A. F. M. (1991). Optimal Operation of Reservoirs for Electric Generation, IEEE Transactions on Power Delivery 6(3): 1101-1107.

Soares, S. and Carneiro, A. A. F. M. (1993). Reservoir Operation Rules for Hydroelectric Power System Optimization, Athens Power Tech, 1993. APT 93. Proceedings. Joint International Power Conference, Vol. 2.

Szyperski, C. (2002). Component Software - Beyond Object Oriented Programming, Addison-Wesley.

Takagi, T. and Sugeno, M. (1985). Fuzzy identification of systems and its applications to modeling and control, IEEE Trans. Syst., Man, Cybern. 15: 116-132.

Yu, Z., Sparrow, F. T. and Bowen, B. H. (1998). A new longterm hydro production scheduling method for maximizing the profit of hydroelectric systems, IEEE Transactions on Power Systems 13(1): 66 - 71.

Zimmermann, H. J. (2001). Fuzzy Set Theory - and its Applications, Kluwer Academic Publishers. 